\title{
LA MOVILIDAD HUMANA EN LA RED DE LAS PALABRAS DE ESTADO
}

\author{
The human mobility in the web of State words
}

Gennaro Avallone*

Resumen. Este artículo tiene por objetivo estudiar los contenidos y las razones que impulsan la mirada Estado-etno-céntrica sobre las migraciones, basada en la combinación entre el pensamiento de Estado y una actitud cultural y política de tipo colonial, que reproduce la jerarquización de las poblaciones mundiales a nivel global. Lo que se propone es una crítica epistemológica y metodológica, ampliamente basada en la obra de Abdelmalek Sayad, que cuestiona la forma hegemónica de observar las migraciones. Al mismo tiempo, ella permite, normativamente, de destacar la necesidad de liberar las migraciones de las palabras de Estado, que son las dominantes en los discursos y las maneras de pensar, a partir del reconocimiento de su historicidad, de las relaciones de fuerza en las que ésta se desarrolla y de su autonomía relativa.

Palabras clave: Pensamiento de Estado; dominación; emigracióninmigración; Abdelmalek Sayad.

\begin{abstract}
This article aims to study contents and reasons that sustain an ethno-centric-State view about migration, based on the combination between State thought and a colonial cultural and political attitude, that reproduces the hierarchization of global population. The article proposes an epistemological and methodological critics, widely based on Abdelmalek Sayad's writings, that questions the hegemonic way to observe and know migration. At the same time, these critics, normatively, allows to highlight the need to free migration from State words, which are dominant in the understanding oh human mobility, beginning by the recognition of migration's historicity, power relations in which migration are made and relative autonomy of migration.
\end{abstract}

Keywords: State thought; domination; emigration-immigration; Abdelmalek Sayad.

\footnotetext{
Universidad de Salerno. Salerno, Italia. E-mail: gavallone@unisa.it. Orcid: 0000-0003-0602$388 X$.
} 


\section{Introducción}

Este artículo tiene por objetivo estudiar los contenidos y las razones que impulsan la mirada sobre las migraciones definida como Estado-etno-céntrica, basada en la combinación entre el pensamiento de Estado y una actitud cultural y política de tipo colonial aunque después de la colonia formalmente entendida. Esta mirada reproduce la jerarquización de las poblaciones mundiales en base a sus diferentes posiciones de fuerza económica y militar, también heredadas de las administraciones coloniales. Lo que se propone es una crítica epistemológica y metodológica que cuestiona la forma hegemónica de observar las migraciones.

Para desarrollar este objetivo, se propondrá, a través de una investigación de escritorio, una re-elaboración de algunos estudios que han criticado las relaciones coloniales y postcoloniales (Quijano, Fanon, Grosfoguel, Mohanty, Arendt), y especialmente los realizados por Abdelmalek Sayad entre 1964 y 1998. Lo que se realizará es una crítica epistemológica a la mirada dominante "sobre" las migraciones, que contribuye a reproducir, al nivel de la organización del pensamiento y del lenguaje, la subordinación de las personas migrantes en las sociedades de inmigración, especialmente cuando ellas son herederas de la subalternidad colonial.

En primer lugar, en el apartado 1, se explicará la relevancia del pensamiento de Estado y de la colonialidad para comprender los vínculos epistemológicos y políticos a través de los cuales son definidas las migraciones. En el apartado 2, se destacará cómo la comprensión hegemónica de las migraciones está subordinada a un código binario y preguntas y respuestas de Estado que marginalizan y trivializan a sus actores principales. En el apartado 3 se pondrá en evidencia cómo la perspectiva analizada reduce a las personas migrantes a la condición de objetos, es decir, como entes subalternos, carentes de subjetividad. Por último, a modo de conclusión, en los apartados 4 y 5, se presentará, normativamente, la necesidad de liberar las migraciones, así como su epistemología y su realidad concreta partiendo de un cuestionamiento de la forma de pensamiento a la que han sido sometidas con el objetivo de reconocer su historicidad así como las relaciones de fuerza en las que éstas se desarrollan.

\section{Las migraciones, entre pensamiento de Estado y colonialidad}

La lógica del pensamiento de Estado y el principio de colonialidad han caracterizado las formas de estudiar las migraciones internacionales a lo largo del tiempo.

Esto es debido, por un lado, al hecho de que las características de las migraciones internacionales han sido tradicionalmente definidas por los Estados, en el sentido de que éstos han establecido históricamente qué 
formas de movilidad humana pueden definirse como migraciones y cuáles no pertenecen a esta categoría, como por ejemplo, las de los turistas o empresarios. Esta división, que opera a nivel jurídico, pero también simbólico, ha sido denominada por Sayad (2010a) como "pensamiento de Estado", cuya lógica se fundamenta en la separación entre nacionales y no nacionales, es decir, entre los que pertenecen de manera legítima al orden político e institucional y los que están presentes, también legalmente, en el territorio estatal pero no de manera legitimada. Dicha separación no solo ha permeado a nivel social e institucional, sino que también ha influido notablemente en el campo de los estudios sociales, que han utilizado las categorías del Estado - como, por ejemplo, las de integración, flujos, clandestino, irregular - para comprender las migraciones sin atender a las referencias históricas y políticas específicas que determinan su compleja realidad.

Por otro lado, las migraciones hacen referencia a relaciones asimétricas tanto de poder como de estatus social, entre poblaciones. Estos tipos de relaciones parten del legado de las relaciones coloniales construidas en los últimos siglos y, más generalmente, del principio de colonialidad, es decir, de una construcción histórica que organiza jerárquicamente las relaciones sociales, culturales y epistémicas entre los diferentes pueblos, basándose en "la imposición de una clasificación racial/étnica de la población mundial" (Quijano, 2000, p. 342). La colonialidad, que funcionó como elemento constitutivo y específico del patrón mundial de poder capitalista, sigue activa en cada ámbito de la vida, tanto cotidiana, como social, afectando de forma concreta a las posibilidades de movilidad espacial, al acceso a los mercados laborales y a la inserción social de las poblaciones en función de la posición que ocupan en la clasificación jerárquica global.

La colonialidad es, por tanto, un principio de organización y dominación, heredado del pasado colonial, pero actualizado en el mundo postcolonial, con consecuencias de orden político y social, pero también epistemológico, al ser constitutivo de las formas hegemónicas de conocer y pensar el mundo. La historia del poder está estrechamente vinculada a los modos en los que es producido el conocimiento. Tal como señala Grosfoguel (2013), el pensamiento moderno viene determinado y alimentado por los que este autor ha denominado como "los cuatro epistemicídios", vinculados todos ellos con la destrucción del conocimiento de las siguientes poblaciones: de musulmanes y judíos durante la conquista de Al-Andalus; de los pueblos indígenas en los continentes americano y asiático; de los africanos reducidos a la esclavitud; y de las mujeres perseguidas como brujas en Europa. Estos genocidios han construido el conocimiento eurocéntrico, que ha marginalizado a lo largo del tiempo a los pueblos colonizados y, entonces, también a los pueblos que han heredado el pasado de objeto colonial. 
Por lo tanto, para cuestionar críticamente lo que sabemos acerca de las migraciones, debemos desnaturalizar las visiones hegemónicas basadas en el pensamiento de Estado y la colonialidad y preguntarnos cómo - con qué palabras y formas de pensar - observamos este fenómeno social. Para ello, es necesario llevar a cabo un análisis de tipo metodológico y epistemológico, con el objetivo de preguntarnos qué supuestos analíticos y en qué manera, se ha construido y desarrollado el conocimiento sobre las migraciones. Se trata, pues, de un ejercicio útil dado que las palabras que utilizamos para observar los fenómenos sociales no son neutrales. Esto es aún más cierto en el caso de las migraciones, estudiadas históricamente a través de un enfoque basado en la centralidad del Estado - entonces, a través de palabras de Estado (Boubeker, 2010) - y fundamentado, por lo tanto, en sus intereses y formas de pensar, alineados con el principio de colonialidad. Al mismo tiempo, este ejercicio es esencial para intentar liberar las migraciones de la definición política y teórica estatal-colonial que les han sido impuestas y cuyos vínculos epistémicos y políticos vigentes someten a las personas migrantes a unas relaciones de dominación que pretenden subordinarlas al Estado y al orden nacional en que están presentes.

\section{La trivialización de las migraciones}

Tanto la observación como la investigación social no son actividades arbitrarias, pues se construyen, organizan y producen de acuerdo a miradas y métodos determinados, dentro de una historia colectiva cuyo campo disciplinar, cultural e institucional establece las modalidades en que esas actividades son definidas, transmitidas, reproducidas o posiblemente cuestionadas. Esto significa que la actividad de investigación tiene una tradición y un conjunto consolidado de referencias teóricas y prácticas, que guían e influyen en las formas concretas de producir conocimiento.

Investigar es realizar una actividad productiva que se desarrolla con referencia a límites, recursos, reglas de conducta y significados compartidos por la comunidad de investigación con ciertas actitudes hacia el mundo que Alvin Gouldner (1970) Ilamó "supuestos de fondo y supuestos del dominio", definidos como el conjunto de creencias, emociones y sentimientos compartidos sobre la humanidad y sus modalidades de acción en campos sociales específicos. La forma en la que se observa e investiga, remite pues a una práctica construida y producida no solo socialmente sino también históricamente, en el sentido de que se basa en una historia de la investigación y del aprendizaje llevada a cabo sobre todo en instituciones universitarias.

La forma de investigar se construye, así como es construido lo que se investiga. El hecho de que cada investigación sea una práctica que construya sus objetos y herramientas, significa que requiere de una reflexión sobre 
sí misma, así como de un autocontrol explicito de sus construcciones y sus modos de funcionamiento. De lo contrario, la actividad de investigación se convierte en una práctica que "no sabe, en realidad, lo que está haciendo", puesto que no conoce "los principios mismos de la comprensión del objeto" (Bourdieu, Wacquant, 1995, p. 178).

En el caso de los estudios sociales sobre movilidad humana internacional, las categorías y los métodos de investigación se construyeron primero en los Estados Unidos a principios del siglo XX (Rauty, 1999), surgiendo más adelante en Europa, en los años 50 (Sayad, 1984), según un enfoque dual basado en una distinción radical: se producirán, por un lado, estudios de la emigración y, por el otro, estudios de la inmigración. Esta división producirá un objeto de investigación dividido, predefinido y jerarquizado, naturalizando la separación entre emigración e inmigración, cuando dicha fractura no existe ni en la biografía de los individuos, ni en la historia de los grupos sociales influenciados y afectados por los movimientos migratorios.

El análisis y la propuesta metodológica de Abdelmalek Sayad partirán de una crítica a esta separación originaria, destacando la necesidad de ir más allá del estudio fragmentado entre la emigración e inmigración, como si fueran realidades sociales y biográficas radicalmente divididas, con el objetivo final de elaborar un análisis comprensivo de las migraciones. Su análisis, se centrará así, por un lado, en el cuestionamiento de la separación entre emigración e inmigración, ya que son "dos dimensiones del mismo fenómeno, [que] no están separadas ni autonomizadas más que de manera determinativa" (Sayad, 2010a, p. 19), y, por el otro, en el reconocimiento de la centralidad del concepto de "migraciones" o emigración-inmigración. Si hay un proceso de inmigración, entonces, al mismo tiempo, hay siempre, de forma inseparable, un proceso de emigración, siendo ambos hechos indisociables. Esta realidad es inmediatamente comprensible a nivel individual pues la persona que emigra de un lugar para inmigrar a otro es la misma, sin dividirse ni convertirse en otro ser. Sin embargo, el Estado, y con él, las sociedades de partida y llegada, así como los que observan y estudian el proceso migratorio, construyen ambos momentos de manera separada, como si inmigración y emigración estuvieran divididos en compartimentos estancos.

De acuerdo con la interpretación de Sayad, quién desarrolló la perspectiva de Pierre Bourdieu (Avallone, Santamaría, 2018), esta construcción es el producto del pensamiento del Estado, que divide la realidad en dos partes, colocando a los nacionales, es decir, los que pertenecen al Estado, en una, y a los no nacionales, es decir, los que no pertenecen al Estado, en otra. Dicha separación es política, pero también es, al mismo tiempo, epistemológica y social, pues actúa tanto sobre las formas en que se conoce la realidad como sobre las representaciones que organiza las relaciones entre las personas. Se 
trata por tanto de una separación que produce una manera homóloga de pensar, clasificar y ordenar las migraciones, basada en la oposición jerárquicamente organizada entre inmigrante y autóctono - donde el primero constituye la parte subalterna en este sistema de representación - que "se postula como el principal binomio en la configuración del esqueleto lingüístico que limita, e incluso determina, el conocimiento de los actuales movimientos de población intercontinentales" (Vives Riera, 2011, p. 67).

El pensamiento de Estado es "la ideología elaborada y reproducida por el Estado, mediante la cual naturaliza sus postulados y crea seres humanos de Estado que reproduzcan espontáneamente sus categorías de pensamiento" (Molinero, 2018, p. 285). Y es que, las categorías de Estado construyen y producen las migraciones, incluyendo etiquetados dicotómicos como, por ejemplo, los de regular o irregular/clandestino; migrante económico y refugiado; integración y expulsión; fronteras internas y fronteras externas. Estas son palabras que emanan del Estado y, por lo tanto, parten de un actor específico, activo en campos particulares de la vida, cuyos intereses propios se convierten en las palabras de observación general y generalizada que emplean los estudios sociales, así como aquellos otros actores, tales como periodistas o políticos, que hablan en el espacio público. Así sucede, que categorías administrativas e institucionales, que responden a intereses políticos específicos, se convierten en las categorías de quienes estudian y observan las migraciones, hasta convertirse en las únicas categorías existentes y, en consecuencia, las únicas palabras y formas de pensamiento disponibles. En otras palabras, la existencia del Estado produce formas de razonar y pensar internalizadas, en el sentido de que:

estas categorías a través de las que pensamos la inmigración (...), categorías que son (...), en suma, políticas, son indudable y objetivamente (es decir, sin saberlo $y$, por consiguiente, independientemente de nuestra voluntad) categorías nacionales, o incluso nacionalistas. (Sayad, 2010a, p. 385-386)

En definitiva, las migraciones se piensan de forma indiscutible $y$ naturalizada utilizando criterios políticos basados en los límites estatales y nacionales. Ellas, así, se definen como un hecho determinado por los Estados, permeando el ámbito de la sociedad y el de las ciencias y observaciones sociales, que reproducen sus formas de pensarlas, observarlas y definirlas. De esta manera, las clasificaciones políticas e institucionales se imponen sobre el fenómeno de forma naturalizada.

Si las categorías para entender las migraciones son categorías de Estado, entonces también las preguntas sobre el fenómeno serán preguntas de Estado. Dado que este fenómeno depende de nuestras categorías de pensamiento y, entonces, de construcción del mundo social y político, reconociendo la 
conexión entre Estado y migración, Sayad destaca un hecho epistemológico, el hecho de que las migraciones se piensan como el Estado pide y quiere que se piensen. De esta manera, cualquier observación de los hechos y las relaciones sociales que involucran la migración, está completamente subordinada a la política, específicamente a la política estatal, afectando así a las características de lo observado, pues en vez de entender esta realidad social como uno entre tantos fenómenos humanos e históricos, se aborda como si de un conjunto de problemas sociales y de orden público se tratara.

La lógica de Estado impuesta a las migraciones reduce su complejidad, porque borra todos los significados sociales, individuales, emocionales y relacionales que cada migración implica para patrocinar solo su lógica política (del Estado) y económica (de la sociedad de inmigración, primero). En consecuencia, las migraciones dejan de ser, tal como afirma Sayad (2010a), "un hecho social total", que influye e involucra a todos los individuos y sus comunidades de pertenencia, y se convierten en un hecho estatal, en un hecho simplificado y parcial. Así, las migraciones son reducidas a una suma de problemas para la sociedad de llegada, desapareciendo de esta forma, las historias de las personas que migran así como las conexiones económicas, militares y geopolíticas entre las áreas de origen y el resto del mundo, determinantes para entender el proceso migratorio, que desde el destino tan solo se percibirá como un problema social. De esta manera, tanto los Estados como las sociedades de llegada se convierten en el centro de atención, construyendo a las personas migrantes como actores completamente marginales o figuras del desorden, con características negativas y molestas.

\section{Las personas migrantes reducidas a objetos subalternos}

Las transformaciones del Estado y la soberanía en las últimas décadas han favorecido la conformación de una suerte de sociedad global o supranacional, que se piensa a través del espejo de las migraciones. Sandro Mezzadra y Maurizio Ricciardi (2013) hablaron de un "pensamiento de la sociedad" para referirse, en combinación con el pensamiento del Estado, al conjunto de categorías y formas de pensar que establecen el espacio de la epistemología política de las migraciones contemporáneas. Lo que se ha verificado ha sido un fortalecimiento del pensamiento jerárquico hacia el fenómeno de la movilidad espacial de las personas, reforzando de esta manera, la primacía de las preguntas, intereses y puntos de vista de las sociedades y Estados de inmigración para reducir en posición subordinada a los principales protagonistas de esta relación, es decir, a las personas migrantes.

Existen numerosos ejemplos de esta construcción de la realidad y las migraciones, donde cabe destacar aquellos reproducidos por los medios de comunicación de masas que utilizan reiterativamente, de forma victimista, 
la retórica del "nosotros" contra "ellos", donde el "nosotros" lo constituye la sociedad nacional, que estaría supuestamente subordinada a los intereses de los extranjeros, beneficiados en perjuicio de la población nativa (Alietti, 2017).

La organización de este pensamiento se registra, de la misma manera, en todos los discursos diarios en los que la población civil naturaliza su construcción jerárquica, situando por encima a los nacionales en cuestiones, como, por ejemplo, cuando se plantea por qué "ayudar" a los inmigrantes cuando hay tantos compatriotas en dificultad, como si el apoyo tuviera una geografía de pertenencia (nacional) como guía.

Este orden del discurso se fundamenta en la generalización de asociaciones sin base científica ni real, como, por ejemplo, la conexión entre el Islam y el terrorismo; entre la irregularidad administrativa y la propensión a cometer delitos; o, entre la movilidad espacial de las personas y la invasión territorial. Se alimenta, por tanto, de palabras, ideas e imágenes discriminatorias y alarmistas (mencionando, por ejemplo, oleadas migratorias de falsos refugiados), que llevan a proponer soluciones demagógicas y vaciadas de sentido político como el eslogan "ayudémoslos en su casa" difundido por parte de la derecha política europea, de manera particular italiana, en las últimas dos décadas (Stille, 2018), que no cuestiona las relaciones internacionales de fuerza ni la reconoce las condiciones de vida y poder, y también de violencia, en las que la voluntad de las personas migrantes se forman.

Las modalidades a través de las cuáles el fenómeno se concibe, define y analiza, están pre-constituidas y anticipan la observación empírica, evidenciando que "no exist[e] otro objeto en relación al cual una problemática venga tan decididamente impuesta de antemano como éste" (Sayad, 2010b, p. 259). Esto significa que es imposible comprender las migraciones si no se indagan "los procesos que la[s] instituyen como objeto de discurso, de gobierno y de conocimiento" (Gil Arauyo, 2010, p. 244). Como puede verse, las migraciones dependen del Estado, de sus categorías, de sus maneras de observar y de sus formas de juzgar y pensar, no solo en términos concretos, políticos o legales, tales como la concesión o denegación de documentos, las expulsiones practicadas o evitadas y las amnistías aprobadas o postergadas, sino también en términos de comprensión, análisis y definición del fenómeno. Por eso, parafraseando a Chandra Mohanty (2008), hablamos de migración bajo el ojo y las palabras del Estado, las cuáles tienden a privar totalmente de autonomía a los sujetos migrantes, pues son definidos de manera exógena, precisamente desde el punto de vista del sujeto - el Estado - que controla y gobierna las fronteras (Mezzadra, 2012), dejando de lado la condición de migrante, que es la de "hombre-mujer en situación de frontera" (Mate, 2018, p. 52). 
El Estado es más que un ente institucional o burocrático detentor del monopolio de la fuerza, es también una "estructura mental" (Bourdieu, 2007), esto es, un sistema de comprensión y organización de la realidad social capaz de imponer estructuras de pensamiento que impregnan las visiones sobre el mundo y la vida en base a principios de división y separación. Pensar el Estado significa, por lo tanto, pensarlo usando sus propias categorías, es decir, utilizando los conceptos y palabras que el propio Estado transfiere a sus ciudadanos, a través de las agencias de socialización, represión y control. De esta manera, las formas de pensar del Estado se naturalizan e interiorizan en las mentes de las personas, sacralizando la defensa, fetichización y reproducción continua de las fronteras.

El hecho de no cuestionar el pensamiento de Estado produce, por una parte, una normalización de la separación social y epistemológica basada en el nacionalismo y, por otra, una realidad jerárquica, determinada por la asimetría entre la condición de pertenencia y la de no pertenencia al orden estatal. Pertenecer significa estar en el lugar adecuado, es decir apropiado, en el sentido de estar en el justo lugar y, propio, en el sentido de ser titular de un derecho de propiedad sobre éste. No pertenecer, por el contrario, significa estar fuera de lugar, es decir, estar fuera de lo propio, y, por lo tanto, ser definido como una presencia ajena, extraña, como aquel que está aquí, en el lugar de inmigración, aunque no debería estarlo.

La presencia del inmigrante es preocupante pues, al ser definido como un peligro potencial constante, requiere de un control continuo. Las migraciones perturban el orden político y simbólico del Estado, puesto que revelan su artificialidad y arbitrariedad, a la par que, sobre todo para las personas con la condición de refugiadas, "ponen en crisis la ficción originaria de la soberanía" (Agamben, 2010, p. 26) y la carencia de fundamentos reales que sustenten la existencia de fronteras que delimiten una unidad nacional. La presencia de los migrantes es, por lo tanto, perturbante para el orden establecido, ya que cuestiona el orden nacional, tanto de sus Estados de origen, al mostrar su incapacidad para retenerlos, como de sus Estados de llegada, al demostrar su incapacidad para frenar su entrada: "lo que el migrante destruye o afecta, cuestiona, revoca, suspende y perturba son los sueños de seguridad absoluta fundados en la identidad de los ciudadanos y el control total de las fronteras físicas y simbólicas (Raimondi, 2016, p. 57).

$\mathrm{Si}$ estar fuera de lugar significa ser "incongruente e inoportuno" (Bourdieu, 2010, p. 16) quiere decir que estar en el país de inmigración, implica ocupar un lugar equivocado. Esta condición, objetivamente incómoda y de subordinación simbólica y emotiva, conlleva el hecho de ser objeto de preocupación constante, por lo que debe ser monitoreado bajo el ojo, tanto de la ciudadanía, como de las instituciones de la sociedad de inmigración, de 
forma similar al colonizado que "está siempre alerta, descifrando difícilmente los múltiples signos del mundo colonial, sin saber nunca si se ha pasado o no, del límite. Frente al mundo determinado por el colonialista, el colonizado siempre se presume culpable" (Fanon, 1994, p. 46). Ser inmigrante implica por lo tanto convivir con una condición de sospecha generalizada: "el inmigrado tiene la sensación de ser vigilado permanentemente" (Sayad, 2010a, p. 290).

La sospecha, que normalmente está asociada de manera naturalizada y automática a un conjunto de prejuicios e ideas predeterminadas, conlleva una doble pena. Es decir, si un inmigrante es investigado en un juicio o es involucrado en un caso judicial, siempre también es su presencia que se va a investigar, independientemente de si es o no el autor de un delito, porque es la migración en sí misma que se considera como un delito. Como ha escrito Sayad (2010, p. 390): "en este caso particular, la delincuencia no es solamente la de los delitos que la policía tiene que conocer, (...) pues se confunde, en lo más profundo de nuestro modo de pensamiento, con la existencia misma del inmigrado y con el hecho mismo de la inmigración".

Esto es evidente, por ejemplo, en la manera en la que normalmente la prensa diaria presenta los hechos de crónica que involucran a migrantes, donde la nacionalidad extranjera se convierte en una circunstancia agravante. Y también se evidencia en la existencia de los Centro de expulsión de los migrantes, aunque ellos no han cometido delitos, o de la expulsión asociada a algunos tipos de condenas penales, como si la inmigración fuera una culpa en sí misma.

Esto sucede solo por el hecho de estar allí, en un lugar donde no debería estar, porque el inmigrante siempre está fuera de lugar: está, pero no debería estar. Esta condición representa su culpa primigenia, siendo un pensamiento arraigado, que se hunde en las estructuras de razonamiento y clasificación del mundo en las que los ciudadanos vienen socializados por las agencias estatales, principalmente la escuela. Se trata pues, de la base sobre la cual proliferan los estereotipos que dificultan la comprensión de la realidad, aunque la convierten en un lugar aparentemente tranquilo y tranquilizador.

Al mismo tiempo, estar constitutivamente fuera de lugar, significa también estar privado de un lugar en el mundo (Arendt, 1982), por lo que la presencia de los migrantes está sometida, en función de los intereses del momento, tanto al uso utilitario como a posibles exageraciones por parte de las sociedades e instituciones de destino. Un ejemplo revelador de ello lo constituyen las declaraciones del ex alcalde de El Ejido, Juan Enciso Ruiz, quién, en el mes de febrero de 2000, durante una revuelta ciudadana contra la presencia marroquí en la ciudad, resumió la actitud del pensamiento estatal y de sociedad hacia las personas migrantes a través de las siguientes palabras: 
"a las ocho de la mañana todos los inmigrantes son pocos, a las ocho de la tarde, sobran todos" (cf. Checa, Arjona, Checa y Olmos, 2010, p. 128).

Estar fuera de lugar, significa para las personas migrantes, que no deberían quedarse donde están, es decir, en el país de inmigración. Su presencia es molesta e inoportuna, pero, sobre todo, no es deseada, puesto que, desde un punto de vista estatal, no debería ocurrir. La presencia de los inmigrantes es, por lo tanto, una presencia tolerada: si deben estar allí, es porque son temporalmente necesarios, por ello, tienen que estar donde y cómo la sociedad de llegada y sus instituciones decidan, sin autonomía personal, puesto que el anfitrión es quién determina lo que el huésped puede hacer.

La relación entre los inmigrantes y la sociedad de inmigración es constitutivamente asimétrica, siendo los primeros subordinados a la segunda, que establece cuáles son las reglas de vida en común y a las que los inmigrantes solo pueden adaptarse. En este tipo de relación social, quienes imponen las normas, formas y condiciones de vida aumentan su poder social ya que, una de las raíces de éste, coincide con la posibilidad de decidir cómo se usa el espacio, además de cómo se usan el tiempo y el dinero (Harvey, 1989).

En el caso de los inmigrantes, por ejemplo, la determinación de la ubicación de los lugares de culto o de la ocupación del espacio público para sus prácticas religiosas, (especialmente, en el caso de los países occidentales, si se trata de la práctica del Islam) constituye una manifestación de este poder. En muchos países del mundo, los ritos religiosos son construidos fácilmente como una amenaza al orden, lo que demuestra que las formas en que se utiliza el espacio no son social o políticamente neutrales, sino que están sujetas a relaciones de fuerza. Quién define cómo se usa el espacio, incrementa su dominio y cuando se refiere a la presencia de inmigrantes en él, las relaciones de poder socialmente existentes son inmediatamente visibles. Es evidente que los mecanismos activados por el pensamiento del Estado también visibilizan y fortalecen esta relación asimétrica, atribuyendo la legitimidad de la acción a la sociedad de inmigración: es la sociedad de llegada la que define cómo el inmigrado debe permanecer y establecer cuál es su lugar.

Esta consideración parece obvia, ya que parece normal pensar que "cada uno decide las normas que rigen su hogar". Sin embargo, la naturalización de esta forma de pensar no es más que una reproducción del funcionamiento de la estructura cognitiva del Estado y de sus miembros, siguiendo un estilo de pensamiento que concibe el territorio del Estado como una propiedad de sus ciudadanos. Si éste es su hogar y, en consecuencia, no es el de los demás, entonces el extranjero se convierte en un huésped expulsable, cuya presencia administrativa o legal puede ser negada, merced a la voluntad arbitraria del anfitrión (De Genova, Peutz, 2010). 
Los "otros" pueden acceder a la casa de los nacionales solo de forma temporal y subalterna, de manera a que su presencia no moleste. En este sentido, el eslogan que reza "los nacionales primero", expresa la idea de que existe una primacía de los nacionales en su propio territorio, definido como un inmenso hogar, articulado en base a una ideología que trasciende los partidos y las regiones, para imperar inequívocamente en todo el territorio del Estado (Molinero, 2018). Este eslogan manifiesta directamente la forma de pensar del Estado, pues se funda en la originaria e incuestionada separación entre nacionales y no nacionales constitutiva del pensamiento de Estado.

Solo el trabajo justifica la presencia en destino de la persona migrante y no de forma constante, pues, sobre todo, en los periodos de crisis o en las áreas con tasas de paro históricamente más altas, puede ser percibido como un ladrón del trabajo de los nacionales. Queda claro, por tanto, el papel residual que se atribuye a los inmigrantes, quiénes solo tienen reconocidas aquellas viviendas, tareas laborales o presencias en lugares públicos que a los nacionales no interesan o rechazan. Es emblemático, en este sentido, cómo el discurso público resalta el hecho de que los trabajos que hacen los inmigrantes son aquellos que los nacionales no quieren, destacando así que el lugar que les es reservado, es residual, indeseado, y, sobre todo, se trata de un espacio que los nacionales han dejado libre y disponible hasta que ellos, y sus instituciones, quieren.

Desde un punto de vista epistemológico, es decir, sobre la forma en que se organiza el conocimiento, los que pertenecen a la dimensión nacional se colocan en la posición de sujetos, siendo quiénes definen a los demás, sometiendo de esta manera a los no nacionales a permanecer en la posición que ellos definan, convirtiéndolos en objetos de observación, y por lo tanto silenciando su propia voz. Así, las personas que migran son constantemente definidas por otros, sin que puedan disponer de autonomía de definición. Están determinadas por puntos de vista externos a ellas, es decir, por personas, grupos e instituciones que tienen tanto sus propios intereses, como sus propias reglas, lógicas y modalidades de conducta. Son vidas que quedan reducidas a ser meros objetos de las palabras de los demás, tal como refleja el debate público donde a menudo periodistas, políticos y "expertos" hablan de las personas que migran como si se tratara de objetos o incluso imágenes, en vez de personas. Esta representación del debate público está basada en la separación entre una humanidad con derecho a hablar, que por lo tanto es activa y protagonista, de una humanidad que es objeto de estas palabras, y por lo tanto es reducida a la condición de "cosa", impidiendo su expresión y convirtiéndola en objeto de los discursos de quiénes sí pueden hablar.

Las personas que migran son objeto de los demás, de sus conocimientos, de sus formas de organizar el pensamiento, de sus palabras y categorías analíticas. 
La subjetividad de las personas migrantes, queda por tanto muy limitada al reducirse su posibilidad de definición, juicio y manifestación. Las personas migrantes son sometidas así a un proceso de homogeneización, definidas por categorías y palabras ya establecidas, indiferentes a las individualidades y heterogeneidades de sus condiciones, biografías y experiencias migratorias, al ser aglutinados y reducidos a una única categoría: la del inmigrante.

Este proceso conduce a una simplificación simbólica, política y cognitiva de la realidad y la vida de las personas que afecta también a su reducción como objetos. Las vidas, en su singularidad excepcional, desaparecen, y solo quedan construcciones generales, homogéneas y simplificadas, que permiten asociar a las personas que migran a determinadas características específicas, transformándolas en abstracciones, como si se tratara de fantasmas, es decir de seres anónimos carentes de humanidad, y, por lo tanto de necesidades y derechos.

Los migrantes, de esta manera, se insertan en una relación epistemológica en la que ocupan la posición de objeto, determinada por otros, anulando así sus vidas y características propias, cuyas definiciones y delimitaciones son determinadas por sujetos, instituciones y fuerzas habilitadas para llevar a cabo esta operación de atribución de características.

Los que definen, tienen el poder de actuar sobre los migrantes, convirtiéndolos en sujetos social y políticamente subordinados, que existen solo en las definiciones aportadas por otros y no por ellos mismos. Son así privados de la posibilidad de autodefinirse, debiendo adherirse a definiciones externas y extrañas pues no solo no están en condiciones de expresarse sino que tienen que hacer frente a la situación permanente de pedir permiso para estar, lo cual, queda claro no solo a nivel jurídico-administrativo sino también a nivel político, social y cultural.

\section{Cuestionar una forma de pensar naturalizada}

La fuerza de las estructuras de pensamiento del Estado, al igual que la de las acciones de éste, radica en el hecho de que están naturalizadas, es decir, que sus esquemas de clasificación se reproducen de forma automática e incuestionada.

El mundo dividido entre nacionales y no nacionales es un mundo de fronteras, activas tanto en la vida política de los Estados y sus relaciones interestatales como en el ámbito de las representaciones simbólicas y las estructuras cognitivas. En este contexto, las fronteras actúan concretamente, pues vienen cotidianamente reproducidas, lo cual se verifica a través de la acción combinada entre las estructuras militares y policiales, así como en las estructuras mentales y de pensamiento objetivadas. 
La ciudadanía nacional es un éxito histórico de esta separación, basada en la distinción formalizada entre los que pertenecen (ciudadanos) de los que no pertenecen (no ciudadanos) y, sobre todo, en la distinción entre ciudadanos y no ciudadanos pobres. De hecho, esta separación solo viene cuestionada por la fuerza del dinero, como demuestra el hecho de que sea posible comprar la ciudadanía de una serie de Estados, simplemente pagando o comprando inmuebles de alto valor económico, en países de la Unión Europea tales como España, Malta, Chipre, Austria, Hungría y Bulgaria (Abrahamian, 2015).

La división del mundo en Estados y fronteras, y, con ello, de las poblaciones en nacionales y no nacionales rara vez se cuestiona, pues se fortalece a través de la invención continua de retóricas e ideologías, como las que recurren a elementos tales como los valores comunes o el interés nacional. Si se aplica una visión no nacionalista, es fácil reconocer que estos temas son construcciones políticas en beneficio de intereses económicos y sociales específicos, que generalmente coinciden con los intereses dominantes y, por lo tanto, no tienen el carácter natural que se tiende a otorgarles.

Todos estos elementos convergen así en la preservación de las fronteras, una construcción tanto geográfica como militar, que justifica, para su defensa externa, la guerra y la sumisión de determinados territorios a alguna forma de protectorado o gobierno imperialista/(neo)colonial. En cambio, para su defensa interna, legitima los controles policiales y la "proliferación de fronteras internas (ya sean imaginarias, simbólicas que escondan luchas económicas o por el poder) y su corolario, [los cuáles, intensifican] los sentimientos de pertenencia local, da[ndo] lugar a prácticas de exclusión, cierre identitária y persecución que pueden conducir a verdaderos pogromos, e incluso a genocidios" (Mbembe, 2011, p. 104).

Es la determinación de una frontera lo que favorece la hipótesis de la guerra y, al mismo tiempo, la conversión del otro en alguien radicalmente diferente, es decir, en un enemigo potencial, sabiendo que, como escribió Primo Levi (2002, p. 4):

habrá muchos, individuos o pueblos, que piensen más o menos conscientemente, que "todo extranjero es un enemigo". En la mayoría de los casos esta convicción yace en el fondo de las almas como una infección latente (...). Pero cuando ésta llega, cuando el dogma no expresado se convierte en la premisa mayor de un silogismo, entonces, al final de la cadena está el Lager.

La lógica impulsora de las fronteras externas es la misma que se aplica internamente para construir la homogeneidad nacional pues el mecanismo utilizado es el mismo que justifica los procesos de asimilación y reconocimiento de la ciudadanía a los extranjeros, no casualmente definidos como "naturalización". Aquellos que son asimilados o solicitan convertirse en 
nacionales, esto es, en "uno de nosotros", son reconocidos como amigos o, mejor dicho, no enemigos. Sayad recuerda que, en este caso, la atribución de hostilidad en realidad solo se suspende, puesto que los migrantes asimilados, siempre serán susceptibles de rebelarse contra dicha asimilación, al ser "naturalmente" diferentes de los nacionales. El naturalizado es un ciudadano cuya condición será siempre reversible a nivel social y cultural si bien a nivel administrativo y legal, conservará su condición de nacional de forma permanente. De esta manera, el naturalizado, siempre vivirá una condición de falta de integridad, puesto que sobre él pesará el hecho de que la condición ciudadana no fue adquirida de manera natural, es decir normal.

El naturalizado vive la imposibilidad de la integración total, pues es "una noción cargada" (Sayad, 2010a, p. 309) que parte de un discurso hecho para producir "un efecto de verdad [...] fundado en la creencia (y en el prejuicio) incluso si mira o mira codiciosamente hacia la ciencia" (Sayad, 2010a, p. 304), al confundir la ciencia social con un mito. Durante una investigación conducida por Sayad, Aicha, una estudiante a la que entrevista, destaca el carácter mítico de la integración, al asociarla al concepto matemático de la integral y su función exponencial pues es como "la curva asintótica que se puede alargar hasta el infinito y que nunca tocará la abscisa. La integración es así, es necesario correr detrás de ella, y cuanto más te acercas más te recuerdan que no es completamente eso" (Sayad, 2010a, p. 370).

La integración aparece y se produce como un significante vacío, si bien acarrea numerosas consecuencias concretas, incluida la reproducción de la separación entre ciudadanos y no nacionales, donde éstos son obligados a integrarse, debiendo cumplir un deber que reproduce una relación de dominación-subalternidad cultural (Bouamama, 2018), mientras los primeros disponen de libertad para decidir la posición que ocuparán en la sociedad los naturalizados. En este sentido, siguiendo las palabras de Aicha, puede verse la imposibilidad de una integración real dado que, aunque sea una posibilidad legal, para el pensamiento de Estado, quiénes la ejerzan, siempre serán percibidos por su condición originaria de migrantes.

\section{Conclusiones}

El análisis de las condiciones de los migrantes en las sociedades de llegada a través de categorías de Estado, tales como la de integración, predeterminan la comprensión del fenómeno, anticipando las respuestas y dirigiendo las investigaciones sociales, así como otras formas de observación y análisis, hacia objetivos cognoscitivos que son los de los Estados y las sociedades de inmigración, oscureciendo las condiciones y las trayectorias de vida de los migrantes mismos. 
Las palabras utilizadas tanto en el discurso científico como en el discurso público para referirse a las migraciones, son palabras de Estado, pues éstas, comúnmente, son observadas desde el punto de vista estatal, y, por ende, de las sociedades de inmigración. Se trata, por tanto, de una mirada basada en las visiones, valores e intereses de una parte de la población nacional y su Estado, ajenos a toda consideración de los intereses de las personas inmigrantes. Dicha percepción puede definirse, así, como "Estado-etno-céntrica", pues se desarrolla privilegiando a una parte del proceso migratorio, la sociedad y el Estado de inmigración, dejando de lado o borrando u olvidando a la otra parte, es decir, tanto a los Estados y las sociedades de emigración como a las personas mismas que emigran-inmigran.

El pensamiento de Estado y el pensamiento de sociedad, en combinación con la herencia colonial que continua a alimentar la dicotomía entre ser y no ser, organizan las modalidades de investigación y producción del conocimiento sobre las migraciones, determinando una constante validación del enfoque metodológico-epistemológico que privilegia las categorías y palabras de Estado en la comprensión de los procesos y experiencias de movilidad humana. Se confirma de esta manera que "el discurso sobre el inmigrado y sobre la inmigración no es otro que un discurso impuesto. Y, por tanto, toda la problemática de la ciencia social de la inmigración es una problemática impuesta" (Sayad, 2008, p. 34). Ir más allá de las palabras de Estado y de las categorías producidas en el marco de las relaciones (post) coloniales es una condición fundamental para liberar de interpretaciones predeterminadas y preguntas predefinidas por las relaciones de fuerza entre Estados, áreas geopolíticas y razas, a los estudios y la comprensión de las migraciones y movilidad humana.

\section{Referencias bibliográficas}

ABRAHAMIAN, Atossa. The Cosmopolites: The Coming of the Global Citizen. New York: Columbia Global Reports, 2015.

AGAMBEN, Giorgio. Medios sin fin: Notas sobre la política. Valencia: Pre-textos, 2010.

ALIETTI, Alfredo (ed.). Razzismi, discriminazioni e disuguaglianze. Analisi e ricerche sull'Italia contemporánea. Milano-Udine: Mimesis, 2017.

ARENDT, Hannah. L'imperialisme. París: Fayard, 1982.

AVALLONE, Gennaro, SANTAMARÍA, ENRIQUE (eds.). Abdelmalek Sayad: una lectura crítica. Migraciones, saberes y luchas (sociales y culturales). Madrid: Dado Ediciones, 2018.

BOUAMAMA, Saïd. Las paradojas de la integración y el universalismo abstracto. In: AVALLONE, Gennaro; SANTAMARÍA, Enrique (eds.). Abdelmalek Sayad: una lectura crítica. Migraciones, saberes y luchas (sociales y culturales). Madrid: Dado Ediciones, p. 93-110, 2018. 
BOUBEKER, Ahmed. Abdelmalek Sayad, pionnier d'une sociologie de l'immigration postcoloniale. In: BANCEL, Nicolas; BERNAULT, Florence et alii (eds.). Ruptures postcoloniales. Les nouveaux visages de la société française. París: La Découverte, p. 37-48, 2010.

BOURDIEU, Pierre. Prefacio. In: SAYAD, Abdelmalek. La doble ausencia. De las ilusiones del emigrado, a los padecimientos del inmigrado. Barcelona: Anthropos, p. 13-17, 2010.

BOURDIEU, Pierre. El sentido práctico. Buenos Aires: Siglo XXI Editores, 2007.

BOURDIEU, Pierre; WACQUANT, Loic. Respuestas por una antropología reflexiva. México: Grijalbo, 1995.

CHECA, Juan Carlos; ARJONA, Ángeles; CHECA Y OLMOS, Francisco, Actitudes recientes hacia los inmigrantes en El Ejido (España). Convergencia. Revista de Ciencias Sociales, v. 17, n. 52, p. 125-154, 2010.

DE GENOVA, Nicholas; PEUTZ, Nathalie. The Deportation Regime: Sovereignty, Space, and the Freedom of Movement. Durham: Duke University press, 2010.

FANON, Frantz. Los condenados de la tierra. México: FCE, 1994.

GIL ARAUYO, Sandra. Una sociología (de las migraciones) para la Resistencia. Empiria, n. 19, p. 235-249, 2010.

GOULDNER, Alvin. The Coming Crisis of Western Sociology. New York: Basic Books, 1970.

GROSFOGUEL, Ramón. Racismo/sexismoepistémico, universidades occidentalizadas y los cuatro genocidios/ epistemicidios del largo siglo XVI. Tabula Rasa, n. 19, p. 31-58, 2013.

HARVEY, David. The urban experience. Oxford: Basil Blackwell, 1989.

LEVI, Primo. Si esto es un hombre. Barcelona: Muchnik Editores, 2002.

MATE, Esteban. De la (ir)relevancia epistémica de las migraciones. A propósito de la edición de la doble ausencia de A. Sayad. In: AVALLONE, Gennaro; SANTAMARÍA, Enrique (eds.). Abdelmalek Sayad: una lectura crítica. Migraciones, saberes y luchas (sociales y culturales). Madrid: Dado Ediciones, p. 35-55, 2018. MBEMBE, Achille. Necropolítica. Barcelona: Editorial Melusina, 2011.

MEZZADRA, Sandro, Capitalismo, migraciones y luchas sociales. La mirada de la autonomía. Nueva sociedad, n. 237, p. 159-178, 2012.

MEZZADRA, Sandro, RICCIARDI, Maurizio. Introduzione. In: MEZZADRA, Sandro; RICCIARDI, Maurizio (eds.). Movimenti indisciplinati. Migrazioni, migranti e discipline scientifiche. Verona: ombre corte, p. 7-28, 2013.

MOHANTY, Chandra. Bajo los ojos de occidente. Academia Feminista y discurso colonial. In: SUÁREZ NAVAZ, Liliana; HERNÁNDEZ, Aída (eds.). Descolonizando el Feminismo: Teorías y Prácticas desde los Márgenes. Madrid: ed. Cátedra, p. 112-161, 2008.

MOLINERO GERBEAU, Yoan. Programas de migración temporal ża utopía del pensamiento de Estado hecha realidad? In: AVALLONE, Gennaro; SANTAMARÍA, Enrique (eds.). Abdelmalek Sayad: una lectura crítica. Migraciones, saberes y luchas (sociales y culturales). Madrid: Dado Ediciones, p. 279-295, 2018. 
QUIJANO, Anibal. Colonialidad del poder y clasificación social. Journal of worldsystems research, v. VI, n. 2, p. 342-386, 2000.

RAUTY, Raffaele. Il sogno infranto. Le scienze sociali e la chiusura delle frontiere all'emigrazione negli Stati Uniti d'America (1924). Roma: manifestolibri, 1999.

RAIMONDI, Fabio. Migranti e Stato. Saggio su Abdelmalek Sayad. Verona: ombre corte, 2016.

SAYAD, Abdelmalek. La doble ausencia. De las ilusiones del emigrado, a los padecimientos del inmigrado. Barcelona: Anthropos, 2010a.

SAYAD, Abdelmalek. Colonialismo y migraciones. Empiria, n. 19, p. 259-261, $2010 b$.

SAYAD, Abdelmalek. L'immigrazione o i paradossi dell'alterità. L'illusione del provvisorio. Verona: ombre corte, 2008.

SAYAD, Abdelmalek, Tendances et Courants des Publications en Sciences Sociales sur I'Immigration en France Depuis 1960. Current Sociology, n. 32, p. 219-304, 1984.

STILLE, Alexander, How Matteo Salvini pulled Italy to the far right. The Guardian, 9 de agosto, 2018.

VIVES RIERA, Antoni. Conflicto cultural y construcción del conocimiento: del choque de civilizaciones a la hibridación creativa. In: Aa.Vv. Formas-otra. Saber, nombrar, narrar, hacer. IV Training Seminar de jóvenes investigadores en Dinámicas Interculturales. Barcellona: Cidob edicions, p. 65-78, 2012. 